\section{Psychiatric Manifestations of Endocrine Disorders}

\author{
Spencer H Conner ${ }^{1}$ and Solomon S Solomon ${ }^{1,2 *}$ \\ ${ }^{1}$ Departments of Medicine and Pharmacology, University of Tennessee
} Health Science Center, Memphis, USA

${ }^{2}$ Medicine and Research Services, Memphis VA Medical Center, Memphis, USA

\begin{abstract}
When studying different endocrine disorders, it has been customary to focus on the hypothalamic-pituitary axis in discussing certain aspects of these disorders. Much less attention has concentrated on the psychiatric symptoms commonly associated with these disorders, and the need for physicians to think with an interdisciplinary approach in achieving the best possible outcomes for their patients. It is our goal through this review to provide a comprehensive assessment of the psychological aspects associated with many of these endocrine disorders. Specifically, we will address the psychological characteristics associated with diabetes, Cushing's syndrome, Addison's disease, hyperthyroidism, hypothyroidism, hyperparathyroidism, hypoparathyroidism, pheochromocytoma, and androgen and estrogen disorders, as well as a discussion of selected psychiatric issues in transgender patients.
\end{abstract}

\section{Introduction}

The endocrine system has been studied extensively from physiological, biochemical, and molecular approaches. However, much less attention has concentrated on the psychological aspects associated with these different endocrine diseases, and the necessity of addressing these psychological issues in order to effectively treat endocrine patients. Often, there is a significant impairment in the quality of life when it comes to these different endocrine diseases, and an interdisciplinary approach is needed in order to achieve the best possible outcome for the patient. It is our goal through this review to provide a comprehensive assessment of the psychological implications associated with different endocrine disorders. Specifically, we will address the psychological aspects associated with diabetes, Cushing's syndrome, Addison's disease, hyperthyroidism, hypothyroidism, hyperparathyroidism, hypoparathyroidism, pheochromocytoma, and androgen and estrogen disorders, as well as a brief correlation of transgender adults.

\section{Adrenal: Cushing's Syndrome and Addison's Disease}

Over the past few decades, a number of authors have found a significant amount of psychological disorders associated with

*Corresponding author: Solomon S Solomon, Medicine and Research Services, Memphis VA Medical, 1030 Jefferson Ave, Memphis, TN 38104, USA, Tel: +1 9015238990I; E-mail: ssolomon@uthsc.edu

Citation: Conner SH, Solomon SS (2017) Psychiatric Manifestations of Endocrine Disorders. J Hum Endocrinol 2: 007.

Received: July 13, 2016; Accepted: May 29, 2017; Published: June 12, 2017

Copyright: (@ 2017 Conner SH and Solomon SS, This is an open-access article distributed under the terms of the Creative Commons Attribution License, which permits unrestricted use, distribution, and reproduction in any medium, provided the original author and source are credited.
Cushing's syndrome. Sonino and Fava [1] found that major depression is a life-threatening complication, which may affect $50-60 \%$ of patients with Cushing's syndrome. They found that it occurs in both the pituitary dependent and independent forms of the disease. Kelly et al., [2] found a similar association with 57\% of 209 Cushing's syndrome patients having a significant psychiatric illness, usually depression. A follow-up study by Sonino et al., [3] found that $54 \%$ of patients with pituitary-dependent Cushing disease had major depression according to DSM-IV criteria. They observed that the depression in Cushing's syndrome was significantly associated with female gender, older age, higher urinary cortisol levels, a relatively more severe clinical condition, and an absence of a pituitary adenoma. Other authors have also found the same correlation between depression and Cushing's syndrome [1,4-7]. While depression is one of the most important psychological symptoms associated with Cushing's syndrome, other symptoms have been noticed. Starkman et al., [8] and Starkman [9] reported that around $66 \%$ of their Cushing's syndrome patients experienced generalized anxiety or panic disorders. Sonino et al., [10] also found a significant association between anxiety and Cushing's syndrome. In this same particular study, the authors also saw there was a significant association in their Cushing's syndrome patients with increased irritable mood, higher levels of stress, and lower physical well-being. Mania and hypomania are other psychological symptoms that have been associated with Cushing's syndrome by a number of authors [11,12].

There has been a significant debate in the literature whether the psychological symptoms of Cushing's syndrome completely resolve after the remission of the disease. Several studies have found significant improvements or even complete remission of anxiety, hypomania, mania, depression, and mood irritability, after correction of the hypercortisolism [2,13-17]. In particular, Dorn et al., [6] found significant improvements of depression in patients after 3, 6, and 12 months, of treatment based on the Hamilton depression rating scale and depressed mood scale. Also of note, it has been postulated by a number of studies that inhibitors of corticosteroids like ketoconazole or metyrapone may be better in treating psychological symptoms of these patients, rather than the antidepressant drugs $[9,18]$.

However; as mentioned, other studies have found delayed treatment or continued presence of psychological symptoms after normalization of cortisol levels. Long-lasting effects of anxiety, depression, attention, and mood, have been seen to persist long after treatment of Cushing's syndrome [19-22]. The effect of excess glucocorticoids causing brain atrophy has been believed to be the mechanism causing the neurocognitive symptoms seen in Cushing's syndrome patients and has been thought to be partially irreversible even after the disease has remitted [23]. Through proton magnetic resonance spectroscopy, Resmini et al., [24] found there was neuronal dysfunction and persistence of neuronal damage in the hippocampus even after the remission of the disease. Dorn et al., [6] has even noted that psychiatric symptoms might even exacerbate after disease remission because of the cortisol decrease. Overall, with the discrepancies of this subject in the literature, it can be said that more long-term studies are needed to answer the question of whether or not there is a continued persistence of psychological symptoms even after the normalization of cortisol levels. 
Addison's disease has been found to present with different psychological symptoms as well. The symptoms of irritability, mood behaviors, distress, depression, and to a minor extent psychosis, have been reported by a number of studies to be associated with the disease [25-27]. Anglin et al., [25] brings up the point that psychiatric symptoms may even be the only symptoms present in Addison's disease patients, so it is important when seeing these symptoms to maintain a high index of suspicion for this potentially fatal condition. Potential mechanisms that have been proposed to explain these neuropsychiatric symptoms of Addison's disease include: electrophysiological; glucocorticoid deficiency; electrolyte and metabolic abnormalities; increased endorphins; and an associated Hashimoto encephalopathy. However, the mechanism remains unknown [28]. Also, in a few studies, it has been found that there is a significant improvement in psychological symptoms once Addison's disease is corrected with appropriate corticosteroid therapy [3,27]. Iwata et al., [29] even suggests that performing blood work for ACTH and cortisol in the field of psychiatry is necessary because Addison's disease can often be overlooked when psychiatric features are present (Table 1).

\begin{tabular}{|c|c|}
\hline Endocrine Condition & Psychiatric Symptoms \\
\hline $\begin{array}{l}\text { Hypercortisolism } \\
\text { Depression }\end{array}$ & $\begin{array}{c}\text { Anxiety, Panic disorders, Irritability, Mania, Hypomania, } \\
\text { Poor self-image hypocortisolism irritability, Distress, } \\
\text { Mood disorders, Depression }\end{array}$ \\
\hline Type 1 Diabetes & $\begin{array}{c}\text { Depression, Psychomotor agitation, Sleeping difficulty, } \\
\text { Eating disorders }\end{array}$ \\
\hline Type 2 Diabetes & Depression, Eating disorders, Poor self-image \\
\hline Hyperthyroidism & $\begin{array}{l}\text { Anxiety, Irritability, Mania, Hypomania, Psychosis, } \\
\text { Insomnia, Attention and Overactivity problems, Depres- } \\
\text { sion, Restlessness, Fatigue, and Delirium }\end{array}$ \\
\hline $\begin{array}{l}\text { Hypothyroidism } \\
\text { Depression }\end{array}$ & $\begin{array}{c}\text { "Myxedema madness", Attention deficits and cognitive } \\
\text { disturbances }\end{array}$ \\
\hline Pheochromocytoma & Anxiety, Panic disorders, Tremulousness \\
\hline Hyperparathyroidism & Anxiety, Depression, Personality changes, Psychosis \\
\hline Hypoparathyroidism & Depression \\
\hline Androgens & $\begin{array}{l}\text { Increased aggression, Anger, Acting out, Dominant } \\
\text { behavior, Antisocial behavior }\end{array}$ \\
\hline Androgens & Increased sexual desire and Seductive behavior \\
\hline Menopause & Depression \\
\hline
\end{tabular}

Table 1: Collective Review of Psychiatric Symptoms associated with Endocrine Conditions.

\section{Type 1 and Type 2 Diabetes}

Type 1 and type 2 diabetes are endocrine disorders, which are also associated with psychiatric symptoms. In a study of 330 type 2 diabetic patients, Derakhshanpour et al., [30] found a significant association with depression and poor self-image, which was noted as having a considerable impact on the consequences of diabetes and the quality of life in the patients. Semenkovich et al., [31] reported the statistic in his study that clinically significant depression is present in one out of every four patients with type 2 diabetes. A number of other authors have also found this association of depression and poor self-image with type 2 diabetic patients [32-34]. As Egede et al., [35] and Nicolau et al., [33] mentioned, physicians need to be aware of the psychiatric symptoms associated with diabetes because when the psychiatric issues of diabetes are not diagnosed and treated, the financial cost to society and the health care system is catastrophic.

Eating disorders are commonly seen in type 2 diabetic patients as well. In a study of 320 type 2 diabetic patients, Nicolau et al., [33] found that $16 \%$ had eating disorders and $12.2 \%$ had binge eating disorders. In their study of 152 type 2 diabetic patients, Celik et al., [36] found similar findings. Eating disorders are also seen in type 1 diabetics where patients will intentionally omit their insulin to induce hyperglycemia and induce loss of glucose in the urine in order to lose weight $[37,38]$. The common denominators for the development of eating disorders in type 1 and type 2 diabetic patients are increased body weight, body dissatisfaction, female gender, a history of dieting, and a history of depression. Clinical signs that should raise suspicion to the physician include poor glycemic control, recurrent episodes of diabetic ketoacidosis, recurrent hypoglycemia secondary to intentional overdose, missed clinical appointments, poor self-esteem, and dietary manipulation [38].

With type 1 diabetes and psychiatric symptoms, Raymond [39] makes the plea that, "Additional research, specifically interventions successfully addressing the behavioral and psychosocial issues in this population, is desperately needed," because, "Behavioral and psychosocial issues in adolescents with DM1 greatly impact their diabetes and general life outcomes." In their study of 295 adolescents with type 1 diabetes, Adal et al., [40] found a significant correlation with depression and anxiety with a reported depression rate of $12.9 \%$. A number of other authors have also found these correlations of psychiatric symptoms with type 1 diabetes including the issue of psychomotor agitation, sleep difficulty, and eating disorders [34,41-44]. Cox et al., [46] brings up the point that type 1 diabetes can be difficult to manage for patients because of three contributing themes. These themes are parental influence, peer influence, and depression, which all can lead to non-compliance in type 1 diabetic patients.

\section{Thyroid: Hyperthyroidism and Hypothyroidism}

When it comes to the subject of hyperthyroidism and hypothyroidism, there have been a number of studies that have found psychological symptoms associated with both hormone imbalances. Stern et al., [47] found in their study of 137 patients with Grave's disease that the psychiatric symptoms of anxiety and irritability were strongly correlated with the disease. Kathol and Delahunt [48] reported that 60\% of their hyperthyroid patients were found to have an anxiety disorder. Furthermore, several other studies have found these symptoms as well as other psychiatric symptoms associated with Grave's disease which include hypomania, mania, depression, psychosis, insomnia, attention and over activity problems, restlessness, fatigue, and delirium $[26,49$ 58]. As far as treatment, there are discrepancies with some studies that have found that psychiatric symptoms like anxiety generally improve with the treatment of hyperthyroidism $[26,48,59]$. However, other studies have reported that psychiatric symptoms persisted despite appropriate anti-thyroid treatment [47,60-63].

As alluded to earlier, hypothyroidism has been associated with a number of psychiatric disorders. As early as 1888 , the effects of hypothyroidism on the psychological state were recognized by the Clinical Society of London in their study of 109 cases with myxedema. They reported that, "delusions and hallucinations occur in nearly half the cases, mainly when the disease is advanced [64]." In 1949, Asher reiterated this relationship of psychosis and hypothyroidism, and coined the infamous term, "myxedematous madness" [28]. Since then, numerous studies have been working to characterize the psychological symptoms associated with hypothyroidism. In a study of 2,142 individuals diagnosed with thyroid disorders, Ittermann et al., [65] found substantial evidence that untreated hypothyroidism is significantly associated with depression. A number of other studies have found this correlation in hypothyroid patients and have observed additional 
psychological problems associated with hypothyroidism including attention deficits and cognitive disturbances [26,50,66-68].

\section{Pheochromocytoma}

In adults and children, psychiatric symptoms like anxiety are known to be associated with pheochromocytoma patients and patients with increased catecholamines. In their study of 93 patients with pheochromocytoma, Anderson et al., [69] found a significant association with the symptoms of anxiety and tremulousness in their patients, which resembled a panic attack. Lenders et al., [70] report that psychological symptoms like anxiety and panic are common in pheochromocytomas and say that these symptoms are seen in $20-40 \%$ of pheochromocytoma patients. In their epidemiological study of 284 patients with pheochromocytoma, Mannelli et al., [71] found a similar percentage of patients with anxiety with $35 \%$ having the symptom. A number of other studies in the literature have furthermore found a significant correlation with psychiatric symptoms like anxiety in pheochromocytoma patients, and it has been reported that anxiety is the fourth most common symptom seen in pheochromocytomas [72]. As a number of authors have pointed out, it is easy for physicians to confuse psychiatric symptoms of pheochromocytomas with other neuropsychiatric disorders, so it is imperative that they keep this diagnosis in mind, especially if a pattern of hypertensive episodes persists or worsens in the patient $[73,74]$.

\section{Parathyroid: Hyperparathyroidism and Hypopara- thyroidism}

Psychiatric disorders have been found to be connected with parathyroid disorders. In his study of 169 hyperparathyroid patients, Espiritu et al., [75] found a significant association between depression and hyperthyroidism. They observed that hyperparathyroid patients were twice as common in developing depression compared to controls, and the severity of hyperparathyroidism as reflected by the serum calcium level is related to depression. Weber et al., [76] also found a significant correlation with $23 \%$ of hyperparathyroid patients having depressive symptoms, and Wilhelm et al., [77] found that $10 \%$ of his 360 hyperparathyroid patients met the DSM-IV criteria for major depression. The literature has further reported that hyperparathyroid patients have a reduced quality of life [78], and Pasieka et al., [79] found a significant improvement in quality of life of patients after parathyroid surgery. Joborn et al., [80] found that out of their 441 hyperparathyroid patients that $23 \%$ had psychiatric symptoms with the most common being anxiety and depression. But, they also reported a number of patients with psychosis. Other studies have confirmed the relationship of hyperparathyroidism to anxiety and depression and in addition have seen an association with personality changes in these patients [81,82]. As far as the mechanisms, Espiritu et al., [75] report, "The mechanism by which PHP (hyperparathyroidism) leads to depression is unclear," and all the psychiatric symptoms associated with hyperparathyroidism for that matter. It has been popular in the literature to see if the psychiatric symptoms of hyperparathyroidism disappear after parathyroidectomy. Wilhelm et al., [77] reported that $90 \%$ of patients, who had depression before the parathyroidectomy, no longer had any depression after the surgery. Also, they reported that a parathyroidectomy in hyperparathyroid patientssaves an estimated 700 to 3,000 dollars per patient per year in anti-depressant medication alone.

Psychiatric symptoms are also evident in hypoparathyroidism. In a study of 62 hypoparathyroid patients, Aggarwal et al., [83] found that neuropsychological dysfunctions were present in one-third of their patients, and these dysfunctions correlated with duration of illness, female gender, serum calcium, and calcium-phosphorus product during follow-up but not with intracranial calcification. Also, Bohrer et al., [84] and Rosa et al., [85] both supported the claim that depression is associated with hypoparathyroidism and that psychiatric disorders seemed predominant in the setting of long-term hypoparathyroidism. As Bohrer et al., [84] mentioned concerning the potential proposed mechanisms of depression with hypoparathyroidism, "The exact cause of depression in cases of hypoparathyroidism is not known." Furthermore, it was found that psychiatric symptoms did not improve with conventional antidepressants and antipsychotics until the serum calcium levels were corrected $[34,85]$.

\section{Androgens}

Androgen disorders have been found to have psychiatric symptoms associated with them as well. In the large study of 4,179 veterans, Mazur et al., [86] found that basal testosterone levels were positively correlated with aggression and antisocial behavior. Archer [87] found through his study that androgen levels have an influence on aggression, and Mazur et al., [86] discovered that androgens are furthermore positively linked to dominant behavior. In the literature, there has been a popular trend to look at prisoners who have committed violent crimes and see if there are any irregularities in hormone levels that might explain their criminal history. Kreuz and Rose [88] found in their assessment of the young criminal population that criminals who committed violent crimes during their adolescence had higher testosterone levels. Dabbs et al., [89] proceeded to measure the free testosterone levels in saliva of 89 prisoners and found a strong association with higher testosterone levels in the prisoners who committed violent crimes versus those who committed non-violent crimes. These studies of criminals; however, should be taken with some reservation though because of the smaller sample sizes and unnatural conditions associated with these studies. In addition to the above literature, a number of other studies have found this association between aggression and androgens and have seen that androgens are associated with other psychiatric symptoms including anger, impulsivity, competitive traits, and violence [90-93]. When looking at adolescents, a number of studies have found a positive correlation of aggression, anger, and acting out, with the contribution of different forms of androgens like testosterone, androstenedione, and DHEA [94-96].

Patients with an androgen deficiency have been found to be associated with psychiatric symptoms. Aydogan et al., [97] is quoted as saying, "Anxiety and depression are the most common and frequently undiagnosed psychological problems associated with male hypogonadism." In their study of 4,393 Vietnam veterans, Booth et al., [98] had their patients' free testosterone levels and depressive symptoms tested. From their study, it was found that there was a significant association between low testosterone levels and depression, and in another study of 869 men over the age of 60, Kurita et al., [99] found this correlation as well. Others have also seen this link between depression and androgen deficiency in their studies [100,101]. As far as treatment, Khera [102] proposes that testosterone deficient patients should be given a trial of testosterone replacement therapy for at least 3 months as testosterone replacement therapy alone may improve clinical symptoms of depression. In the meta-analysis of 355 depressed patients with hypogonadism, Zarrouf et al., [101] further supported testosterone treatment when reporting that there was a significant improvement of the Hamilton depression rating scale among patients who were administered testosterone replacement therapy. 


\section{Menopausae, Estrogen, and Progesterone}

In women, the transition to menopause and its hormonal alterations has been associated with increased depression. In a study of 376 women near menopause, Mauas et al., [103] found a high prevalence of a newly depressed mood among these women, who had no history of depression before menopause. The authors attributed these findings to the ever changing hormonal setting seen during menopause. In addition, their study made the claim that a diagnosis of depressive disorder was 2.5 times more likely to occur in the menopausal transition than premenopausal. Freeman et al., [104] and Gordon et al., [105] both found similar findings saying that the menopause transition is associated with a two to fourfold increased risk of major depressive disorder. These findings are consistent with the results of the SWAN (Study of Women's Health across the Nation) of 3,302 women aged 42 to 52 [106]. The study showed that the odds of depressive symptoms significantly increased as women progressed through the menopausal transition. As far as the mechanism to explain the increased risk of depressive symptoms in menopause, a number of mechanisms have been proposed, but the exact cause is still unknown [105,107]. It has been found by a number of studies that hormonal therapies like estrogen are extremely effective in all menopausal symptoms including depression $[13,108,109]$. Dibonaventura et al., [110] brings up an important point in his paper saying that depression around the menopausal period worsens a patient's quality of life but also causes more of a burden on health care resources and increases costs, so physicians need to be aware of the potential development of depression in women going through menopause.

Estrogen and progesterone also influence the psychological behavior of an individual. In a study of 48 menopausal women, Sherwin [111] gave treatments of estrogen and progestin to her patients. She found that sexual desire and arousal were significantly higher in her treatment group compared with her placebo group. Nathorst-Boos et al., [112] did a similar study giving their patients treatments of transdermal estradiol and found that the frequencies of sexual activity, sexual fantasies, and degree of sexual enjoyment were increased. Wiklund et al., [113] further showed, in their study with transdermal estradiol, that there was an increase in feelings of physical attraction and sexual satisfaction compared to their placebo group. In addition, drugs like tibolone, which is a second generation SERM (selective estrogen receptor modulator), may even be beneficial after surgical menopause because of its effects in improving mood and sexual behavior [114,115].

\section{Correlate: Transgender Adults and Endocrinological Aspects}

Through their work reviewing ten different studies from eight different countries spanning over forty years, De Cuypere et al., [116] provided the most accurate statistics available of prevalence in transgender adults. They reported the prevalence from these studies ranged from 1:11,900 to 1:45,000 for Male-to Female individuals (MtF) and 1:30,400 to 1:200,000 for Female-to-Male (FtM) individuals. As rare as these statistics might seem, it is still important for healthcare professionals to know the best way to assist transgender adults in order to maximize the overall health of these individuals. This is where the World Professional Association for Transgender Health (WPATH) comes into play who is an international, multidisciplinary, professional association whose mission is to promote evidence-based care and respect for transsexual and transgender health. One of their main goals is to provide guidance to health professionals in how to provide the best care possible for transgender patients through their Standards of Care manual [117].

The importance of effective hormonal treatment in transgender patients is made evident through the study of Murad et al., [118] He found that gender dysphoria can mostly be alleviated by treatment, and many individuals will find a gender role that is comfortable for them as a result, even if it differs from their gender assigned at birth. Green et al., [119] found across different studies that satisfaction rates of sexual reassignment patients ranged from $87 \%$ of Male to Female ( $\mathrm{MtF}$ ) patients to $97 \%$ of Female to Male (FtM) patients, and regrets were extremely rare [120]. Medical interventions carry risks however, and physicians must weigh the risks and benefits when considering hormonal therapy in transgender patients. Estrogens of feminizing hormone therapy significantly increase the risk of venous thromboembolic events, particularly in patients who smoke and patients who are over 40. Furthermore, estrogens significantly increase the risk of developing cardiovascular events, high triglycerides levels, and high liver enzyme levels, in MtF patients. Also, estrogens have been found to increase the risk of type 2 diabetes, hypertension, and prolactinoma [117]. In FtM patients, masculinizing hormone therapy involving testosterone and other steroids is known to significantly increase the risk of polycythemia and weight gain. In addition, testosterone therapy in FtM patients has been linked to increasing the risk of lipid disorders, liver enzyme elevations, and psychiatric symptoms in patients with underlying psychiatric disorders. These psychiatric symptoms include bipolar, schizoaffective, and other disorders that may include manic or psychotic symptoms [117]. Fertility is another issue endocrinologists must keep in mind before starting hormonal therapy. Masculinizing and feminizing hormones affects fertility, so the endocrinologist should discuss these issues with the patient and provide information on sperm-preservation and embryo freezing options if needed.

The World Professional Association for Transgender Health also provides guidelines to physicians for treating transgender adolescents with hormonal therapy if they meet a particular set of criteria and their parents or caretakers give consent. The goal is to suppress puberty through hormonal treatment with $\mathrm{GnRH}$ analogues to stop the production of testosterone secretion in males or estrogen and progesterone secretion in females. This is done in order to prevent the development of secondary sexual characteristics that are not desired which would lead to more years of intense gender dysphoria. The adolescent's physical development as well as the hormonal regiment should be under strict supervision by a pediatric endocrinologist. This hormonal therapy given to the youth differs substantially from adults and is adapted to take into account the somatic, emotional, and mental development that occurs throughout adolescence [121].

\section{Conclusion}

As outlined through this extensive review of the literature, psychological symptoms are an important aspect in a variety of endocrine conditions. It is our hope that physicians will now be more aware of these psychological issues so that they are able to treat their patients in a more concise and effective manner. In the future, further research and studies need to be performed because most of the mechanisms to explain how psychiatric symptoms, in patients with different endocrine disorders, arise are still unknown. In addition, treatment aspects of some of the different endocrine disorders need to be further investigated because there are discrepancies in the literature as to what degree correction of the hormonal issues will alleviate the psychiatric symptoms associated with the disorder. In summary and as 
emphasized throughout this literature review, we believe it is vital for the physicians to think with an interdisciplinary approach when treating endocrine disorders, in order to provide the best quality of life and achieve the best possible outcomes for their patients.

\section{Acknowledgement}

1) Veterans Association Medical Center, Medicine and Research Services, Memphis, TN 38104, USA

2) University of Tennessee Health Science Center, Departments of Medicine and Pharmacology, Memphis, TN 38163, USA

\section{References}

1. Sonino N, Fava GA (1998) Psychosomatic aspects of Cushing's disease. Psychother Psychosom 67: 140-146.

2. Kelly WF, Kelly MJ, Faragher B (1996) A prospective study of psychiatric and psychological aspects of Cushing's syndrome. Clin Endocrinol (Oxf) 45: 715-720.

3. Sonino N, Fava GA, Raffi AR, Boscaro M, Fallo F (1998) Clinical correlates of major depression in Cushing's disease. Psychopathology 31: 302-306.

4. Cohen SI (1980) Cushing's syndrome: a psychiatric study of 29 patients. $\mathrm{Br}$ J Psychiatry 136: 120-124.

5. Dorn LD, Burgess ES, Dubbert B, Simpson SE, Friedman T, et al. (1995) Psychopathology in patients with endogenous Cushing's syndrome: 'atypical' or melancholic features. Clin Endocrinol (Oxf) 43: 433-442.

6. Dorn LD, Burgess ES, Friedman TC, Dubbert B, Gold PW, et al. (1997) The longitudinal course of psychopathology in Cushing's syndrome after correction of hypercortisolism. J Clin Endocrinol Metab 82: 912-919.

7. Kelly WF, Checkley SA, Bender DA, Mashiter K (1983) Cushing's syndrome and depression--a prospective study of 26 patients. Br J Psychiatry 142:1619

8. Starkman MN, Schteingart DE, Schork MA (1981) Depressed mood and other psychiatric manifestations of Cushing's syndrome: relationship to hormone levels. Psychosom Med 43: 3-18.

9. Starkman MN (2013) Neuropsychiatric findings in Cushing's syndrome and exogenous glucocorticoid administration. Endocrinol Metab Clin North Am 42: $477-488$.

10. Sonino N, Fallo F, Fava GA (2006) Psychological aspects of primary aldosteronism. Psychother Psychosom 75: 327-330.

11. Haskett RF (1985) Diagnostic categorization of psychiatric disturbance in Cushing's syndrome. Am J Psychiatry 142: 911-916.

12. Kelly WF (1996) Psychiatric aspects of Cushing's syndrome. QJM 89: 543 551.

13. Cohen LS, Soares CN, Poitras JR, Prouty J, Alexander AB, Shifren JL, et al. (2003) Short-term use of estradiol for depression in perimenopausal and postmenopausal women: a preliminary report. Am J Psychiatry 160: 15191522

14. Hirsch D, Orr G, Kantarovich V, Hermesh H, Stern E, et al. (2000). Cushing's syndrome presenting as a schizophrenia-like psychotic state. Isr J Psychiatry Relat Sci 37:46-50

15. Sonino N, Fava GA, Belluardo P, Girelli ME, Boscaro M (1993) Course of depression in Cushing's syndrome: response to treatment and comparison with Graves' disease. Horm Res 39: 202-206.

16. Starkman MN, Schteingart DE, Schork MA (1986) Cushing's syndrome after treatment: changes in cortisol and ACTH levels, and amelioration of the depressive syndrome. Psychiatry Res 19: 177-178.

17. Verhelst JA, Trainer PJ, Howlett TA, Perry L, Rees LH, et al. (1991) Short and long-term responses to metyrapone in the medical management of 91 patients with Cushing's syndrome. Clin Endocrinol (Oxf) 35: 169-178.
18. Fava GA, Sonino N, Morphy MA (1987) Major depression associated with endocrine disease. Psychiatr Dev 5: 321-348.

19. Dorn LD, Cerrone $P(2000)$ Cognitive function in patients with Cushing syndrome: a longitudinal perspective. Clin Nurs Res 9: 420-440.

20. Forget $\mathrm{H}$, Lacroix A, Cohen $\mathrm{H}$ (2002) Persistent cognitive impairment following surgical treatment of Cushing's syndrome. Psychoneuroendocrinology 27: $367-383$.

21. Heald AH, Ghosh S, Bray S, Gibson C, Anderson SG, et al. (2004). Longterm negative impact on quality of life in patients with successfully treated Cushing's disease. Clin. Endocrinol (Oxf) 61: 458-465.

22. Pivonello R, Simeoli C, De Martino MC, Cozzolino A, De Leo M, et al. (2015) Neuropsychiatric disorders in Cushing's syndrome. Front Neurosci 9: 129.

23. Bourdeau I, Bard C, Noël B, Leclerc I, Cordeau MP, et al. (2002) Loss of brain volume in endogenous Cushing's syndrome and its reversibility after correction of hypercortisolism. J Clin Endocrinol Metab 87: 1949-1954.

24. Resmini E, Santos A, Gómez-Anson B, López-Mourelo O, Pires P, et al. (2013) Hippocampal dysfunction in cured Cushing's syndrome patients, detected by (1) H-MR-spectroscopy. Clin Endocrinol (Oxf) 79: 700-707.

25. Anglin RE, Rosebush PI, Mazurek MF (2006) The neuropsychiatric profile of Addison's disease: revisiting a forgotten phenomenon. J Neuropsychiatry Clin Neurosci 18: 450-459.

26. Fava GA, Sonino N, Morphy MA (1993) Psychosomatic view of endocrine disorders. Psychother Psychosom 59: 20-33.

27. Williams RH (1970) Metabolism and mentation. J Clin Endocrinol Metab 31 461- 479 .

28. Asher R (1949) Myxedematous madness. Br Med J 9: 555-562.

29. Iwata M, Hazama GI, Shirayama Y, Ueta T, Yoshioka S, et al. (2004) A case of Addison's disease presented with depression as a first symptom. Seishin Shinkeigaku Zasshi 106: 1110-1116.

30. Derakhshanpur F, Vakili MA, Farsinia M, Mirkarimi K (2015) Depression and Quality of Life in Patients With Type 2 Diabetes. Iran Red Crescent Med J 17: 27676.

31. Semenkovich K, Brown ME, Svrakic DM, Lustman PJ (2015) Depression in type 2 diabetes mellitus: prevalence, impact, and treatment. Drugs 75 : 577-587.

32. de Groot M, Doyle T, Averyt J, Risaliti C, Shubroo J (2015) Depressive symptoms and type 2 diabetes mellitus in rural appalachia: an 18-month follow-up study. Int J Psychiatry Med 48: 263-277.

33. Nicolau J, Masmiquel L (2013) Diabetes mellitus and depressive disorder, an undesirable association. Endocrinol Nutr 60: 583-589.

34. Willis T (1971) Diabetes: A Medical Odyssey. USV Pharmaceutical Corp Tuckahoe, New York, USA.

35. Egede LE, Zheng D, Simpson K (2002) Comorbid depression is associated with increased health care use and expenditures in individuals with diabetes. Diabetes Care 25: 464-470

36. Celik S, Kayar Y, Önem Akçakaya R, Türkyılmaz Uyar E, Kalkan K, et al. (2015) Correlation of binge eating disorder with level of depression and glycemic control in type 2 diabetes mellitus patients. Gen Hosp Psychiatry 37: 116-119.

37. Goebel-Fabbri AE (2009) Disturbed eating behaviors and eating disorders in type 1 diabetes: clinical significance and treatment recommendations. Curr Diab Rep 9:133-139.

38. Pinhas-Hamiel O, Levy-Shraga Y (2013) Eating disorders in adolescents with type 2 and type 1 diabetes. Curr Diabetes Rep13: 289-297.

39. Raymond J (2015) Updates in behavioural and psychosocial literature in adolescents with type 1 diabetes. Curr Opin Endocrinol Diabetes Obes 22: 265-259. 
40. Adal E, Önal Z, Ersen A, Yalçın K, Önal H, et al. (2015) Recognizing the psychosocial aspects of type 1 diabetes in adolescents. J Clin Res Pediatr Endocrinol 7: 57-62

41. Bächle C, Lange K, Stahl-Pehe A, Castillo K, Holl RW, et al (2015) Associations between $\mathrm{HbA} 1 \mathrm{c}$ and depressive symptoms in young adults with early-onset type 1 diabetes. Psychoneuroendocrinology 55: 48-58.

42. Colton PA, Olmsted MP, Daneman D, Farquhar JC, Wong H, (2015) Eating Disorders in Girls and Women With Type 1 Diabetes: A Longitudinal Study of Prevalence, Onset, Remission, and Recurrence. Diabetes Care 38: 1212 1217

43. Maia AC, Braga Ade A, Paes F, Machado S, Nardi AE, et al. (2014) Psychiatric comorbidity in diabetes type 1: a cross-sectional observational study. Rev Assoc Med Bras 60: 59-62.

44. Moulton CD, Pickup JC, Ismail K (2015) The link between depression and diabetes: the search for shared mechanisms. Lancet Diabetes Endocrino 3: 461-471.

45. Philippi ST, Cardoso MG, Koritar P, Alvarenga M (2013) Risk behaviors for eating disorder in adolescents and adults with type 1 diabetes. Rev Bras Psiquiatr 35: 150-156.

46. Cox L, Hunt J (2015) Factors that affect adolescents' adherence to diabetes treatment. Nurs Child Young People 27: 16-21.

47. Stern RA, Robinson B, Thorner AR, Arruda JE, Prohaska ML, et al. (1996) A survey study of neuropsychiatric complaints in patients with Graves' disease. J Neuropsychiatry Clin Neurosci 8: 181-185.

48. Kathol RG, Delahunt JW (1986) The relationship of anxiety and depression to symptoms of hyperthyroidism using operational criteria. Gen Hosp Psychiatry $8: 23-28$.

49. Bové KB, Watt T, Vogel A, Hegedüs L, Bjoerner JB, et al. (2014) Anxiety and depression are more prevalent in patients with graves' disease than in patients with nodulargoitre. Eur Thyroid J 3: 173-178.

50. Brownlie BE, Rae AM, Walshe JW, Wells JE (2000) Psychoses associated with thyrotoxicosis - 'thyrotoxic psychosis.' A report of 18 cases, with statistical analysis of incidence. Eur J Endocrinol 142: 438-444.

51. Demet MM, Özmen B, Deveci A, Boyvoda S, Adgüzel H, et al. (2002) Depression and anxiety in hyperthyroidism. Arch Med Res 33: 552-556.

52. Guo SF (1993) Postpartum depression. Zhonghua Fu Chan Ke Za Zhi 28: 532-533, 569

53. Hage MP, Azar ST 2012) The link between thyroid function and depression. J Thyroid Res 2012: 590648.

54. Hendrick V, Altshuler L, Whybrow P (1998) Psychoneuroendocrinology of mood disorders: the hypothalamic-pituitary-thyroid axis. Psychiatr Clin North Am 21: 277-292.

55. Kung AW (1995) Life events, daily stresses and coping in patients with Graves' disease. Clin Endocrinol (Oxf) 42: 303-308.

56. Matsubayashi S, Tamai H, Matsumoto $\mathrm{Y}$, Tamagana K, Mukuta T, et al. (1996) Graves' disease after the onset of panic disorder. Psychother Psychosom 65: 277-280.

57. Rodewig K (1993) Psychosomatic aspects of hyperthyroidism with special reference to Basedow's disease- An overview. Psychother Psychosom Med Psychol 43: 271-277.

58. Trzepacz, PT, Klein I, Roberts M, Greenhouse J, Levey GS (1989) Graves' disease: an analysis of thyroid hormone levels and hyperthyroid signs and symptoms. Am J Med 87: 558-561.

59. Vogel A, Elberling TV, Hording M, Dock J, Rasmussen AK, et al. (2007) Affective symptoms and cognitive functions in the acute phase of Graves thyrotoxicosis. Psychoneuroendocrinology 32: 36-43.

60. Bommer M, Eversmann T, Pickardt R, Leonhardt A, Naber D, et al. Psychopathological and neuropsychological symptoms in patients with subclinical and remitted hyperthyroidism. Klin Wochenschr 68: 552-558.
61. Bunevicius R, Velickiene D, Prange AJ (2005) Mood and anxiety disorders in women with treated hyperthyroidism and ophthalmopathy caused by Graves' disease. Gen Hosp Psychiatry 27: 133-139.

62. Fahrenfort JJ, Wilterdink AM, van der Veen EA (2000) Long-term residual complaints and psychosocial sequelae after remission of hyperthyroidism. Psychoneuroendocrinology 25: 201-211.

63. Perrild H, Hansen JM, Arnung K, Olsen PZ, Danielsen U (1986) Intellectual impairment after hyperthyroidism. Acta Endocrinol (Copenh) 112: 185-191.

64. Clinical Society of London (1888) Report of a Committee of the Clinical Society of London, Nominated December 14, 1883, to Investigate the Subject of Myxoedema. Longmans, Green, and Company, London, UK.

65. Ittermann T, Völzke H, Baumeister SE, Appel K, Grabe HJ (2015) Diagnosed thyroid disorders are associated with depression and anxiety. Soc Psychiatry Psychiatr Epidemiol 50: 1417-1425.

66. Almeida C, Brasil M, Costa AJL, Reis FAA, Reuters V, et al. (2007) Subclinical hypothyroidism: psychiatric disorders and symptoms. The Revista Brasileira de Psiquiatri 29: 157-159.

67. Larisch R, Kley K, Nikolaus S, Sitte W, Franz M, et al. (2004) Depression and anxiety in different thyroid function states. Horm Metab Res 36: 650-653.

68. Yu D, Zhou H, Yang Y, Jiang Y, Wang T, et al. (2015) The bidirectional effects of hypothyroidism and hyperthyroidism on anxiety- and depression-like behaviors in rats. Horm Behav 69: 106-115.

69. Anderson NE, Chung K, Willoughby E, Croxson MS (2013) Neurological manifestations of phaeochromocytomas and secretory paragangliomas: a reappraisal. J Neurol Neurosurg Psychiatry 84: 452-457.

70. Lenders JW, Eisenhofer G, Mannelli M, Pacak K (2005) Phaeochromocytoma. Lancet 366: 665-675.

71. Mannelli M, Wikgren M, Karling P, Adolfsson R, Norrback KF (2014) Relative hypo- and hypercortisolism are both associated with depression and lower quality of life in bipolar disorder: a cross-sectional study. PLoS One 9: 98682.

72. Manger WM, Gifford RW (1982) Hypertension secondary to pheochromocytoma. Bull NY Acad Med 58: 139-158.

73. Gökçe O, Gökçe C, Günel S, Arisoy S, Arisoy E, et al. (1991) Pheochromocytoma presenting with headache, panic attacks and jaundice in a child. Headache 31: 473-475.

74. Zardawi IM (2013) Phaeochromocytoma masquerading as anxiety and depression. Am J Case Rep14: 161-163.

75. Espiritu RP, Kearns AE, Vickers KS, Grant C, Ryu E, et al. (2011) Depression in primary hyperparathyroidism: prevalence and benefit of surgery. $J$ Clin Endocrinol Metab 96: 1737-1745

76. Weber T, Keller M, Hense I, Pietsch A, Hinz U, et al. (2007) Effect of parathyroidectomy on quality of life and neuropsychological symptoms in primary hyperparathyroidism. World J Surg 31: 1202-1209.

77. Wilhelm SM, Lee J, Prinz RA (2004) Major depression due to primary hyperparathyroidism: a frequent and correctable disorder. Am Surg 70: 175-179.

78. Coker LH, Rorie K, Cantley L, Kirkland K, Stump D, et al. (2005) Primary hyperparathyroidism, cognition, and health-related quality of life. Ann Surg 242: 642-650.

79. Pasieka JL, Parsons LL (1998) Prospective surgical outcome study of relief of symptoms following surgery in patients with primary hyperparathyroidism. World J Surg 22: 513-518.

80. Joborn C, Hetta J, Palmér M, Akerström G, Ljunghall S (1986) Psychiatric symptomatology in patients with primary h70perparathyroidism. Ups J Med Sci 91: 77-87.

81. Chan AK, Duh QY, Katz MH, Siperstein AE, Clark OH (1995) Clinical manifestations of primary hyperparathyroidism before and after parathyroidectomy. A case-control study. Ann Surg 222: 401-414. 
82. Solomon BL, Schaaf M, Smallridge RC (1994) Psychologic symptoms before and after parathyroid surgery. Am J Med 96: 101-106.

83. Aggarwal S, Kailash S, Sagar R, Tripathi M, Sreenivas V, et al. (2013) Neuropsychological dysfunction in idiopathic hypoparathyroidism and its relationship with intracranial calcification and serum total calcium. Eur J Endocrinol 168: 895-903

84. Bohrer T, Krannich JH (2007) Depression as a manifestation of latent chronic hypoparathyroidism. World J Biol Psychiatry 8: 56-59.

85. Rosa RG, Barros AJ, de Lima AR, Lorenzi W, Da Rosa RR, et al. (2014) Mood disorder as a manifestation of primary hypoparathyroidism: a case report. J Med Case Rep 8: 326.

86. Mazur A, Booth A (1998) Testosterone and dominance in men. Behav Brain Sci 21: 353-397.

87. Archer J (2006) Testosterone and human aggression: an evaluation of the challenge hypothesis. Neurosci Biobehav Rev 30: 319-345.

88. Kreuz LE, Rose RM (1972) Assessment of aggressive behavior and plasma testosterone in a young criminal population. Psychosom Med 34: 321-332.

89. Dabbs JM, Frady RL, Carr TS, Besch NF (1987) Saliva testosterone and criminal violence in young adult prison inmates. Psychosom Med 49: 174 182.

90. Chichinadze KN, Domianidze TR, Matitaishvili TTs, Chichinadze NK, Lazarashvili AG (2010) Possible relation of plasma testosterone level to aggressive behavior of male prisoners. Bull Exp Biol Med 149: 7-9.

91. Christiansen K (2004) Behavioural correlates of testosterone. Testosterone, Action, Deficiency, Substitution. Springer Verlag, Berlin, Germany.

92. Ehrenkranz J, Bliss E, Sheard MH (1974) Plasma testosterone: correlation with aggressive behavior and social dominance in man. Psychosom Med 36: 469-475.

93. Sánchez-Martín JR, Azurmendi A, Pascual-Sagastizabal E, Cardas J, Braza $\mathrm{F}$, et al. (2011) Androgen levels and anger and impulsivity measures as predictors of physical, verbal and indirect aggression in boys and girls. Psychoneuroendocrinology 36: 750-760.

94. Azurmendi A, Braza F, Sorozabal A, García A, Braza P, et al. (2005) Cog nitive abilities, androgen levels, and body mass index in 5-year-old children. Hormones and Behaviour 48: 187-195.

95. Inoff-Germain G, Arnold GS, Nottleman ED, Chrousos LG (1988) Relations between hormone levels and observational measures of aggressive behavior of young adolescents in family interactions. Dev Psychol 24: 129-139.

96. van Goozen SH, Matthys W, Cohen-Kettenis PT, Thijssen JH, van Engeland $\mathrm{H}$, et al. (1998) Adrenal androgens and aggression in conduct disorder prepubertal boys and normal controls. Biol Psychiatry 43: 156-158.

97. Aydogan U, Aydogdu A, Akbulut H, Sonmez A, Yuksel S, et al. (2012) Increased frequency of anxiety, depression, quality of life and sexual life in young hypogonadotropic hypogonadal males and impacts of testosterone replacement therapy on these conditions. Endocr J 59: 1099-1105.

98. Booth A, Johnson DR, Granger DA (1999) Testosterone and men's depression: the role of social behavior. J Health Soc Behav 40: 130-140.

99. Kurita N, Horie S, Yamazaki S, Otoshi K, Otani K, et al. (2014) Low Testosterone levels, depressive symptoms, and falls in older men: a cross-sectional study. J Am Med Dir Assoc 15: 30-35.

100. Rupprecht R, Rupprecht M, Rupprecht C, Noder M, Schwarz W (1988) Different reactivity of the hypothalamo-pituitary-gonadal-axis in depression and normal controls. Pharmacopsychiatry 21: 438-439.

101. Zarrouff FA, Artz S, Griffith J, Sirbu C, Kommor M (2009) Testosterone and depression: systematic review and meta-analysis. J Psychiatr Pract 15: 289305.

102. Khera M (2013) Patients with testosterone deficit syndrome and depression Arch Esp Urol 66: 729-736.
103. Mauas V, Kopala-Sibley DC, Zuroff DC (2014) Depressive symptoms in the transition to menopause: the roles of irritability, personality vulnerability, and self-regulation. Arch Womens Ment Health 17: 279-289.

104. Freeman EW, Sammel MD, Lin H, Nelson DB (2006) Associations of hormones and menopausal status with depressed mood in women with no history of depression. Arch Gen Psychiatry 63: 375-382.

105. Gordon JL, Girdler SS (2014) Hormone replacement therapy in the treatment of perimenopausal depression. Curr Psychiatry Rep 16: 517.

106. Bromberger JT, Matthews KA, Schott LL, Brockwell S, Avis NE, et al. (2007) Depressive symptoms during the menopausal transition: The Study of Women's Health across the Nation (SWAN) J Affect Disord 103: 267-272.

107. Brown JP, Gallicchio L, Flaws JA, Tracy JK (2009) Relations among menopausal symptoms, sleep disturbance and depressive symptoms in midlife. Maturitas 62: 184-189.

108. Schmidt PJ, Nieman L, Danaceau MA, Tobin MB, Roca CA, et al. (2000) Estrogen replacement in perimenopause-related depression: a preliminary report. Am J Obstet Gynecol 183: 414-420.

109. Soares CN, Almeida OP, Joffe H, Cohen LS (2001) Efficacy of estradiol for the treatment of depressive disorders in perimenopausal women: a double-blind, randomized, placebo-controlled trial. Arch Gen Psychiatry 58: 529534.

110. DiBonaventura MD, Wagner JS, Alvir J, Whiteley J (2012) Depression, quality of life, work productivity, resource use, and costs among women experiencing menopause and hot flashes: A Cross-Sectional Study. Prim Care Companion CNS Disord 14: 1410

111. Sherwin BB (1991) The impact of different doses of estrogen and progestin on mood and sexual behavior in postmenopausal women. J Clin Endocrinol Metab 72: 336-343.

112. Nathorst-Boos J, Wiklund I, Mattsson LA, Sandin K, Von Schoultz B (1993) Is sexual life influenced by transdermal estrogen therapy? A double blind placebo controlled study in postmenopausal women. Acta Obstet Gynecol Scand 72: 656-660.

113. Wiklund I, Karlberg J, Mattsson LA (1993) Quality of life of postmenopausal women on a regimen of transdermal estradiol therapy: A double-blind placebo-controlled study. Am J Obstet Gynecol 168: 824-830.

114. Somunkiran A, Erel CT, Demirci F, Senturk ML (2007) The effect of tibolone versus 17 beta-estradiol on climacteric symptoms in women with surgical menopause: A randomized, cross-over study. Maturitas 56: 61-68.

115. Voss S, Quail D, Dawson A, Bäckström T, Aguas F, et al. (2002) A randomised, double-blind trial comparing raloxifene $\mathrm{HCl}$ and continuous combined hormone replacement therapy in postmenopausal women: Effects on compliance and quality of life. BJOG 109: 874-885.

116. De Cuypere, G, Van Hemelrijck M, Michel A, Carael, B, Heylens G, et al (2007) Prevalence and demography of transsexualism in Belgium. Eur Psychiatry 22: 137-141.

117. Coleman E, Bockting W, Botzer M, Cohen-Kettenis PT, DeCuypere G, et al. (2012) Standards of Care for the Health of Transsexual, Transgender, and Gender-Nonconforming People, Version 7. International Journal of Transgenderism 13: 165- 232

118. Murad MH, Elamin MB, Garcia MZ, Mullan RJ, Murad A, et al. (2010) Hormonal therapy and sex reassignment: A systematic review and meta-analysis of quality of life and psychosocial outcomes. Clin Endocrinol (Oxf) 72: 214-231.

119. Green R, Fleming D (1990) Transsexual surgery follow-up: Status in the 1990s. Annual Review of Sex Research 1: 163-174.

120. Pfäfflin F (1993) Regrets after sex reassignment surgery. Journal of Psychology \& Human Sexuality 5: 69-85.

121. Hembree WC, Cohen-Kettenis P, Delemarre-van de Waal HA, Gooren LJ, Meyer WJ 3rd, et al. (2009) Endocrine treatment of transsexual persons: An Endocrine Society clinical practice guideline. J Clin Endocrinol Metab 94: 3132-3154. 
